\title{
EFEITO DA TEMPERATURA E DA LUZ NO DESENVOLVIMENTO DE PLÂNTULAS DE MILHO
}

\author{
MOZAMBANI, Amália Estela ${ }^{1}$ \\ BICUDO, Sílvio José ${ }^{2}$
}

Recebido em: $2008-08-28$

Aprovado em: 2009-02-02

ISSUE DOI: 10.3738/1982.2278.138

\begin{abstract}
RESUMO: O objetivo deste trabalho, foi estudar os efeitos da temperatura e da luz no desenvolvimento de plântulas de dois cultivares de milho (Zea mays L.), Zeneca-8392 e Exeler/Ciba. Os ensaios foram realizados em câmaras climatizadas com controle de temperatura e de luz. Foram semeadas cinco repetições de dezesseis sementes, em tubetes, a cinco centímetros de profundidade, para cada tratamento. Foram definidos dezoito tratamentos por cultivar, com temperaturas constantes de 10; 25 e $35^{\circ} \mathrm{C}$, temperaturas alternadas de $10-25 ; 10-35$ e $25-35^{\circ} \mathrm{C}$; e três regimes luminosos: luminosidade constante, ausência de luz e alternância de luz/escuro com oito horas de luz. As avaliações foram feitas quando as plântulas apresentaram quatro folhas definitivas, tendo sido determinados o comprimento do mesocótilo e do coleóptilo e a altura de plântulas. O tratamento que promoveu menor comprimento do mesocótilo foi a temperatura alternada de $10-35^{\circ} \mathrm{C}$ com luz constante, para os dois cultivares. A temperatura, a luz e o genótipo influenciam no desenvolvimento do mesocótilo e do coleóptilo de plântulas de milho. O estiolamento das plantas e do mesocótilo foi proporcionado por combinações entre fotoperíodo e temperatura e não somente pela ausência de luz.
\end{abstract}

Palavras-chave: Coleóptilo. Mesocótilo. Gramíneas. Morfologia.

\section{TEMPERATURE AND LIGHT EFFECTS ON THE DEVELOPMENT OF CORN SEEDLINGS.}

\begin{abstract}
SUMMARY: The aim of the present research was to study the effects of temperature and light on seedlings development of two cultivars of corn (Zea mays. L.), Zeneca-8392 and Exeler/Ciba. The experiment was done under climatic chamber conditions with light and temperature control. Eighteen treatments consisted of combinations of constant temperatures (10,25 and $35 \mathrm{C})$ or alternate temperatures $\left(10-25,10-35\right.$ and $\left.25-35^{\circ} \mathrm{C}\right)$ with different photoperiodic regimes $(0,8$ and 24 hours of light). Plants were grown in pots with 16 plant/pot and 5 replications per treatment. Seedling were evaluated for subcrown internode length, coleoptile length and plant height, starting at the four true leave stage. The tratment that promoted the lowest subcrown internode length was the combination of alternate temperature $\left(10-35^{\circ} \mathrm{C}\right)$ with constant light for both cultivars. Temperature, light and genotype have some effects on the development of corn seedlings. Plants and subcrown internode etiolation was not only due to light absence but also to combinations of photoperiodic and temperature regimes.
\end{abstract}

Keywords: Coleoptile. Subcrown internode. Grass-plants. Morphology.

\footnotetext{
1 Eng. Agr., Profa. Dra. Curso de Agronomia do Centro Universitário Moura Lacerda, Av. Dr. Oscar de Moura Lacerda, 1520, Cep 14076-510.

2 Eng. Agr., Prof. Ass. Dr. Dep. de Agricultura e Melhoramento Vegetal/FCA/UNESP, Caixa Postal 237, Cep 18603-970 Botucatu, S.P.
} 


\section{INTRODUÇÃO}

O milho se constitui, em termos mundiais, num produto agrícola com importante papel sócio-econômico, trata-se de um dos alimentos básicos de grande parte das populações latino-americanas.

Aumentos na produtividade das plantas cultivadas podem ser obtidos através de alterações em aspectos morfo-fisiológicos. Sendo o mesocótilo e o coleóptilo caracteres morfológicos que podem ser alterados por fatores ambientais resultando em benefício para as plantas.

Martin et al (1988) relataram que o estabelecimento de plântulas e a sobrevivência em solos secos são melhorados quando a coroa radicular desenvolve-se próximo à semente, comparado ao desenvolvimento próximo à superfície do solo. $\mathrm{O}$ comprimento do mesocótilo e subsequente localização da coroa podem ter um papel preponderante no desenvolvimento da planta, em período de estiagem.

A relação entre o comprimento do mesocótilo e a sobrevivência de cevada no inverno foi estudada por Dofing e Schimidt (1985), que mediram o comprimento do mesocótilo de plântulas de cultivares de cevada em ambiente controlado, concluindo que mesocótilos curtos (ou coroas profundas) estão associados com mais altos níveis de sobrevivência no inverno, em ampla faixa de condições ambientais.

Martin et al (1988), estudando oito cultivares de trigo e de cevada, com duas intensidades de luz e quatro regimes de temperatura do solo $\left(13,2,17,2,20,2\right.$ e $\left.26,3^{\circ} \mathrm{C}\right)$, verificaram que tanto o trigo como a cevada tiveram o mesocótilo mais curto quando cultivados na presença do que na ausência de luz. Com a redução da temperatura do solo, o mesocótilo teve menor crescimento em ambas as espécies. Cultivares de trigo responderam igualmente aos tratamentos de luz e temperatura do solo; no entanto, foram observadas respostas diferentes para luz e temperatura em cevada.

Segundo Dofing e Schimidt (1984), as expressões fenotípicas, profundidade da coroa e comprimento do mesocótilo, são influenciadas por componentes genéticos e ambientais.

Mozambani (1995), estudando o efeito das temperaturas constantes de 15, 25 e $35^{\circ} \mathrm{C}$ e alternadas de $15-25 ; 15-35$ e $25-35^{\circ} \mathrm{C}$ no comprimento do mesocótilo de plântulas de quatro cultivares de trigo, observou que a maior diferença de comprimento do mesocótilo entre os cultivares ocorreu nas mais baixas temperaturas; o menor comprimento ocorreu à temperatura alternada de $15-35^{\circ} \mathrm{C}$ para os quatro cultivares, ou seja, a temperatura alternada determinante na definição do comprimento do mesocótilo. 
As folhas de plantas de poáceas alongam-se no escuro permanecendo enroladas, com visíveis sintomas de estiolamento, com pouco desenvolvimento dos cloroplastos e baixa atividade de muitas enzimas (HOPKINS, 1995).

Poulos e Allan (1987), em pesquisa sobre a profundidade da coroa e comprimento do mesocótilo e do coleóptilo em trigo, verificaram que o comprimento do coleóptilo mostrou correlação com altura de planta, comprimento do mesocótilo e com a emergência de plântulas. A expressão dessas características tem sido descrita como controlada por fatores genéticos; entretanto, os efeitos ambientais, combinados com o efeito genético podem ser responsáveis pela variabilidade entre associações dessas características para diferentes populações de plântulas.

A profundidade de semeadura e a temperatura podem afetar o comprimento do coleóptilo, bem como o estabelecimento da plântula (PURI ; QUALSET, 1978).

Embora o coleóptilo seja, muitas vezes, referenciado como um broto, morfologicamente é uma folha e sua resposta à luz é típica de uma folha. No escuro, os coleóptilos de aveia e milho permanecem pequenos mas, quando são expostos à luz, suas taxas de crescimento se aceleram (COSGROVE, 1994).

A falta de desenvolvimento de raízes fasciculadas ao redor da semente em solo seco tem sido citada como a principal causa da baixa sobrevivência de plântulas em regiões semi-áridas (HYDER et al. 1971).

Considerando que os fatores ambientais causam alterações morfológicas em plantas e, consequentemente, afetam a produtividade das mesmas, foi desenvolvida a presente pesquisa, partindo da hipótese de que a temperatura e a luz apresentam influência no desenvolvimento do mesocótilo, do coleóptilo e na altura de plântulas de milho.

\section{MATERIAL E MÉTODOS}

Foram utilizadas sementes de milho ( Zea mays L.) cultivares Zeneca 8392 (híbrido simples) e Exeler/Ciba (híbrido triplo), submetidos a seis regimes de temperatura e três regimes de luz.

As sementes foram colocadas em tubetes, contendo o substrato Plantmax, produto elaborado com vermiculita e material orgânico de origem vegetal, isento de pragas, microrganismos patogênicos e sementes de plantas invasoras. Foram utilizadas 16 sementes por repetição a $5 \mathrm{~cm}$ de profundidade, constituindo-se de 5 repetições para 
cada tratamento, resultando em 80 sementes por tratamento. Os tratamentos foram identificados por temperaturas constantes de $10 ; 25$ e $35^{\circ} \mathrm{C}$ e temperaturas alternadas de 10-25; 10-35 e 25-35; e três regimes luminosos: luminosidade constante, ausência de luz e alternância luz/escuro, com fotoperíodo de 8 horas, simulando condições de dia e noite.

As sementes utilizadas foram padronizadas em peso usando balança e comprimento, largura e espessura, com auxílio de paquímetro, visando minimizar a interferência de fatores, tais como quantidade de reservas nutricionais da semente, que pudessem influenciar nos resultados.

Quando 95\% das plântulas apresentaram quatro folhas definitivas, foi determinado o comprimento do mesocótilo, do coleóptilo e altura das plântulas. As medições foram feitas com régua milimetrada e os resultados expressos em $\mathrm{cm}$.

O delineamento experimental utilizado foi o inteiramente casualizado, definindo um fatorial $2 \times 6$ e outro $2 \times 3$, correspondendo a dois cultivares e seis regimes de temperatura e dois cultivares e três regimes de luz, respectivamente.

A análise estatística foi realizada com o intuito de analisar separadamente o comportamento dos dois cultivares quando submetidos aos mesmos tratamentos.

As comparações de médias entre regimes de temperatura e entre regimes de luz foram feitas através do Teste de Tukey e as comparações de médias entre cultivares, pelo Teste $\mathrm{F}$, ao nível de $5 \%$ de probabilidade.

\section{RESULTADOS E DISCUSSÃO}

Efeito da temperatura e da luz no comprimento do mesocótilo $(\mathrm{cm})$ de plântulas de milho.

O comprimento do mesocótilo em milho foi alterado conforme os regimes de temperatura e de luz a que foi submetido (Tabelas 01 e 02). A ausência de luz (Tabela 02) é prejudicial ao desenvolvimento da planta porque determina aumento acentuado no comprimento do mesocótilo, tornando o sistema radicular superficial. Segundo Martin et al. (1988), o estabelecimento de plântulas e a sobrevivência em solos secos são melhorados quando a coroa radicular se desenvolve próximo à semente, comparado a situações de desenvolvimento próximo à superfície do solo.

Para ambos os cultivares de milho, a temperatura mais indicada para obter o menor comprimento do mesocótilo foi de $10-35^{\circ} \mathrm{C}$, sendo que a temperatura constante de $25^{\circ} \mathrm{C}$ promoveu um acréscimo no comprimento do mesocótilo (Tabela 03), 
resultando em sistema radicular superficial e, portanto, mais sensível ao défice hídrico e térmico. Na ausência de luz (Tabela 04) houve maior comprimento do mesocótilo e o regime de luz constante foi o que promoveu menor comprimento do mesocótilo, nos cultivares Zeneca-8392 e Exeler/Ciba.

$\mathrm{O}$ tratamento com $25^{\circ} \mathrm{C}$ sem luz proporcionou maior comprimento do mesocótilo para os dois cultivares, (Tabela 5), apresentando o estiolamento do mesocótilo, o que concorda com Hopkins (1995), ao concluir que o primeiro entrenó, o mesocótilo de plântulas de poáceas, se alonga excessivamente no escuro, e com Martin, et al. (1988), que verificaram que o trigo e a cevada tiveram mesocótilos mais curtos quando cultivados na presença do que na ausência de luz. Apesar do fator ausência de luz causar estiolamento em plântulas, a $25^{\circ} \mathrm{C}$ sem luz, a influência da temperatura parece ser importante, uma vez que nos demais tratamentos com ausência de luz $\left(10^{\circ} \mathrm{C}\right.$; $35^{\circ} \mathrm{C} ; 10-25^{\circ} \mathrm{C} ; \quad 10-35$ e $25-35^{\circ} \mathrm{C}$ sem luz) o comprimento do mesocótilo não foi acentuado.

No tratamento com $10-35^{\circ} \mathrm{C}$ com luz constante nota-se que ocorreram os menores valores de comprimento de mesocótilo para os dois cultivares (Tabela 05). Segundo Martin et al. (1988), esse fato é benéfico porque ocorre melhoria no estabelecimento de plântulas e sobrevivência das mesmas em solos secos, pois, a coroa radicular se desenvolve próximo à semente, favorecendo o aprofundamento do sistema radicular.

As diferenças genéticas entre os cultivares podem ter sido responsáveis pelas respostas distintas quanto ao comprimento do mesocótilo.

O estiolamento do mesocótilo ocorreu de acordo com as diferentes combinações de temperatura e luz a que a cultura foi submetida e não somente pela ausência de luz, como concluiu Hopkins (1995).

Efeito da temperatura e da luz no comprimento do coleóptilo de plântulas de milho:

Nas Tabelas 01 e 02 são apresentadas as diferenças entre os regimes de temperatura e de luz estudados, indicando que a $25^{\circ} \mathrm{C}$ e no tratamento sem luz, ocorre o maior comprimento do coleóptilo em relação aos demais regimes de temperaturas e dos demais regimes de luz. A temperatura de $35^{\circ} \mathrm{C}$ apresentou o menor comprimento do coleóptilo, diferindo significativamente dos demais tratamentos.

O maior e o menor comprimento do coleóptilo ocorreram nas temperaturas de 25 e $35^{\circ} \mathrm{C}$ (Tabela 03) e nos tratamentos com ausência de luz e luz constante 
(Tabela 04), respectivamente para os dois cultivares.

Através das Tabelas 03 e 04 pode-se verificar que os dois cultivares de milho apresentaram valores de comprimento de coleóptilo significativamente diferentes, quando submetidos aos regimes de temperatura e luz, sendo que o cultivar Zeneca8392 sempre apresentou maior valor de comprimento de coleóptilo.

O maior crescimento do coleóptilo nos cultivares de milho submetidos ao tratamento com ausência de luz foi devido ao estiolamento das plântulas nestas condições, causando também um crescimento proporcional no comprimento do coleóptilo (Tabela 04).

Esses resultados diferem do apresentado por Cosgrove (1994) ao concluir que, no escuro, os coleóptilos de aveia e milho permanecem pequenos mas, quando expostos à luz, suas taxas de crescimento aumentam.

O maior comprimento do coleóptilo para os dois cultivares foi obtido no tratamento $25^{\circ} \mathrm{C}$ sem luz, e o menor comprimento foi proporcionado no tratamento a $35^{\circ} \mathrm{C}$ com luz constante, (Tabela 05).

$\mathrm{O}$ tratamento a $25^{\circ} \mathrm{C}$ sem luz, que acarretou maior comprimento do coleóptilo, também ocasionou o maior comprimento do mesocótilo e maior altura de plântulas, embora em proporção menos acentuada.

A diferença entre os dois cultivares de milho (Tabela 05), ocorreu nos tratamentos $10^{\circ} \mathrm{C}$ sem luz, $10^{\circ} \mathrm{C}$ com luz constante, $25^{\circ} \mathrm{C}$ sem luz, $35^{\circ} \mathrm{C}$ com luz constante, $10-25^{\circ} \mathrm{C}$ com luz constante, $10-25^{\circ} \mathrm{C}$ com luz alternada , $10-35^{\circ} \mathrm{C}$ sem luz, $10-35^{\circ} \mathrm{C}$ com luz constante, $25-35^{\circ} \mathrm{C}$ sem luz e $25-35^{\circ} \mathrm{C}$ com luz constante.

$\mathrm{O}$ fator genético parece ser predominante no que se refere às diferenças relativas ao comprimento do coleóptilo entre os dois cultivares quando submetidos aos diferentes tratamentos, uma vez que os cultivares não diferem em tratamentos específicos.

Efeito da temperatura e da luz na altura de plântulas de milho

A temperatura e a luz influem de maneira significativa no crescimento de plântulas dos cultivares de milho estudados. A temperatura de $25-35^{\circ} \mathrm{C}$ alternada, apresentou a maior altura de plântulas de milho (Tabela 01). A ausência de luz promoveu crescimento acentuado nas plântulas em função do estiolamento causado nestas condições (Tabela 02).

O cultivar Zeneca-8392 diferiu do Exeler/Ciba em todos os regimes de temperatura (Tabela 03), indicando que o genótipo dos cultivares age de maneira distinta de acordo com a temperatura a que está submetida a planta. 
A luz atuou decisivamente nos dois cultivares, de forma significativamente diferenciada em todos os regimes de luz (Tabela 04).

A maior e menor altura de plântulas ocorreu nas temperaturas de $25-35^{\circ} \mathrm{C}$ e $10^{\circ} \mathrm{C}$ e nos tratamentos com ausência e luz constante, respectivamente, para os dois cultivares de milho (Tabelas 03 e 04).

Embora os dois cultivares de milho difiram em função da temperatura e luz no que se refere à altura de plântulas, reagem de maneira semelhante dentro de determinada temperatura e luz, ou seja, a maior e menor altura de plântulas é proporcionada pelos mesmos tratamentos de temperatura e luz nos dois cultivares.

A menor altura de plântulas na temperatura de $10^{\circ} \mathrm{C}$ foi devido ao fato dessa ser inferior a temperatura ótima para essa espécie, o que pode reprimir seu crescimento. A altura elevada com ausência de luz foi devido ao estiolamento causado por esse tratamento, considerando que o milho é exigente em intensidade luminosa. Resultados semelhantes também foram encontrados por Hopkins (1995), que comentou que o crescimento de plântulas no escuro levam ao estiolamento.

A altura das plantas varia de acordo com o tratamento, sendo que a $25^{\circ} \mathrm{C} \mathrm{com}$ ausência de luz, foi o que proporcionou maior altura de plântulas para os dois cultivares. Nos demais tratamentos com ausência de luz a $10^{\circ} \mathrm{C} ; 10-25^{\circ} \mathrm{C} ; 10-35^{\circ} \mathrm{C}$ e $25-35^{\circ} \mathrm{C}$, a altura das plântulas não foi tão acentuada como quando a $25^{\circ} \mathrm{C}$ (Tabela 05), levando a concluir que o estiolamento ocorre dependendo do efeito combinado da temperatura e da luz, e não somente pela ausência de luz.

Uma possível causa da altura das plântulas de milho não ser elevada a $10^{\circ} \mathrm{C}$ sem luz, $10-25^{\circ} \mathrm{C}$ sem luz e $10-35^{\circ} \mathrm{C}$ sem luz, pode ser o fato de que a baixas temperaturas, no caso $10^{\circ} \mathrm{C}$, a taxa de fotossíntese é reduzida ou nula e, consequentemente, a taxa de crescimento da plântula diminui, e a $25^{\circ} \mathrm{C}$, que é considerada temperatura ótima para milho, a taxa de fotossíntese aumenta e contribui para que haja aumento da altura de plântulas.

$\mathrm{O}$ tratamento que causou maior crescimento das plântulas, $25^{\circ} \mathrm{C}$ sem luz, foi o que proporcionou maior comprimento do mesocótilo e do coleóptilo, concordando com Poulos \& Allan (1987) ao concluírem que os comprimentos do mesocótilo e coleóptilo têm mostrado correlação com altura de plântulas, sendo controlados por fatores genéticos combinados com fatores ambientais.

Os dois cultivares de milho diferiram significativamente em altura de plântulas (Tabela 05) nos tratamentos a $10^{\circ} \mathrm{C}$ sem luz; na temperatura de $25^{\circ} \mathrm{C}$ em todos 
regimes de luz; $35^{\circ} \mathrm{C}$ com luz constante; $35^{\circ} \mathrm{C}$ com luz alternada; em todos os tratamentos com temperaturas de $10-25^{\circ} \mathrm{C} ; 10-35^{\circ} \mathrm{C}$ com luz alternada; $25-35^{\circ} \mathrm{C}$ sem luz; $25-35^{\circ} \mathrm{C}$ com luz constante e $25-35^{\circ} \mathrm{C}$ com luz alternada.

Os dados obtidos mostram que a temperatura e a luz têm influência na morfologia de plântulas de milho. Este efeito pode ser observado em outras poáceas, tais como cevada (DOFING; SCHIMIDT, 1985). Os cultivares testados diferiram significativamente quanto ao comprimento do mesocótilo, comprimento do coleóptilo e altura de plântulas, de acordo com os diferentes regimes de luz e temperatura. A ausência de luz causou elevado crescimento do mesocótilo e menos acentuado do coleóptilo.

A temperatura e a luz mostraram maior influência no desenvolvimento do mesocótilo quando comparado ao do coleóptilo.

Do ponto de vista prático, o melhor tratamento a fim de promover o menor comprimento do mesocótilo foi o tratamento a $10-35^{\circ} \mathrm{C}$ com luz constante, para os dois cultivares, situação essa que corresponde a regiões com dias quentes e longos e noites frias. Portanto a adequação de temperatura e luz, e consequentemente a escolha da região para cultivo, é importante para promover melhor desenvolvimento de plântulas de diferentes cultivares de milho.

\section{CONCLUSÃO}

Baseado nas condições em que o experimento foi conduzido, pode-se concluir que:

- Temperatura e luz têm efeito decisivo no crescimento do mesocótilo e do coleóptilo de plântulas dos dois cultivares de milho testados.

- O comprimento do mesocótilo e do coleóptilo tem correlação com a altura de plântulas.

- O comprimento do mesocótilo e do coleóptilo são variáveis de acordo com o genótipo, e regimes de temperatura e luz a que está submetida a planta.

- Os regimes de temperatura e luz atuam de maneira distinta na morfologia dos diferentes cultivares de milho.

- O estiolamento de plantas e do mesocótilo são ocasionados por combinações entre luz e temperatura e não somente pela ausência de luz. 


\section{REFERÊNCIAS}

COSGROVE, D. J. Photomodulation of growth. In: KENDRICK, R. E.; KRONENBERG, G. H. M. Photomorphogenesis in plants. Netherlands: Kluwer Academic Publishers, 1994. p.631-658,

DOFING, S. M.; SCHIMIDT, J. W. Inheritance of subcrown internode length in a winter barley cross. Crop.Sci. v. 24, p.692-694, 1984.

DOFING, S. M.; SCHIMIDT, J. W. Relationship between subcrown internode length and winter survival en winter barley. Crop.Sci., v.25, p.690-692, 1985.

HOPKINS, W. G. Photomorphogenesis-Responding to light. In: INTRODUCTION to plant physiology. London: The University of Western Ontario, 1995. p. 341-361.

HYDER, D. N; EVERSON, A. C.; BEMENT, R. E. Seedling morphology and seedlings failures with blue grama. J. Range Manage. v. 24, p.287-292, 1971.

MARTIN, J. M.; SMITH, C. W.; FERGUSON, A. H. Subcrown internode length of spring wheat and barley as influence by light and soil temperature. Agron. J. v. 80, p.571-573, 1988.

MOZAMBANI, A. E. Efeito da temperatura e de diferentes dosagens dos fungicidas triadimenol e tebuconazole em plantas de trigo ( Triticum aestivum L.), no estádio vegetativo. 1995. 120p. Dissertação (Mestrado em Agronomia). Faculdade de Ciências Agronômicas. Universidade Estadual Paulista. Botucatu.

POULOS, J. M.; ALLAN, R. E. Genetics studies of grown depth and subcrown internode lenght in winter wheat. Crop. Sci. v.27, 1987. p. 1109-1113.

PURI, Y. P.; QUALSET, C. O. Effects of seed size and seedling rate on yield and other characteristics of durum wheat. Phyton. J. v. 36, p.41-51, 1978.

TABELA 01. Médias de comprimento $(\mathrm{cm})$ de mesocótilo e coleóptilo e altura de plântulas de dois cultivares de milho, submetidos a diferentes regimes de temperatura.

Temperatura

\begin{tabular}{lcccccc} 
Avaliações & $10^{\circ} \mathrm{C}$ & $25^{\circ} \mathrm{C}$ & $35^{\circ} \mathrm{C}$ & $10-25^{\circ} \mathrm{C}$ & $10-35^{\circ} \mathrm{C}$ & $25-35^{\circ} \mathrm{C}$ \\
\hline $\begin{array}{l}\text { Comprimento } \\
\text { do mesocótilo }\end{array}$ & $3.35^{\mathrm{b}}$ & $7.76^{\mathrm{a}}$ & $3.05^{\mathrm{b}}$ & $1.69^{\mathrm{c}}$ & $1.33^{\mathrm{c}}$ & $2.53^{\mathrm{b}}$ \\
& & & & & & \\
$\begin{array}{l}\text { Comprimento } \\
\text { do coleóptilo }\end{array}$ & $2.87^{\mathrm{b}}$ & $3.64^{\mathrm{a}}$ & $2.38^{\mathrm{c}}$ & $3.13^{\mathrm{b}}$ & $2.78^{\mathrm{b}}$ & $2.90^{\mathrm{b}}$ \\
& & & & & \\
$\begin{array}{l}\text { Altura de } \\
\text { plântulas }\end{array}$ & $14.09^{\mathrm{e}}$ & $31.00^{\mathrm{b}}$ & $26.94^{\mathrm{c}}$ & $17.89^{\mathrm{d}}$ & $19.55^{\mathrm{d}}$ & $33.55^{\mathrm{a}}$ \\
$\begin{array}{l}\text { Médias seguidas de letras iguais, na linha, não diferem significativamente pelo Teste de Tukey, a nível de } \\
\text { 5\% de probabilidade. }\end{array}$
\end{tabular}


TABELA 02. Médias de comprimento $(\mathrm{cm})$ de mesocótilo e coleóptilo e altura de plântulas de dois cultivares de milho, submetidos a diferentes regimes de luz.

\begin{tabular}{lccc}
\hline Luz & Ausente & Constante & $\begin{array}{c}\text { Alternada (8 horas de } \\
\text { fotoperíodo) }\end{array}$ \\
\hline $\begin{array}{c}\text { Comprimento do } \\
\text { mesocótilo }\end{array}$ & $5.67^{\mathrm{a}}$ & $2.48^{\mathrm{b}}$ & $2.61^{\mathrm{b}}$ \\
$\begin{array}{c}\text { Comprimento do } \\
\text { coleóptilo }\end{array}$ & $3.95^{\mathrm{a}}$ & $2.42^{\mathrm{c}}$ & $2.74^{\mathrm{b}}$ \\
$\quad \begin{array}{l}\text { Altura de } \\
\text { plântulas }\end{array}$ & $28.07^{\mathrm{a}}$ & $20.03^{\mathrm{c}}$ & $24.65^{\mathrm{b}}$ \\
\hline $\begin{array}{l}\text { Médias seguidas de letras iguais, na linha, não diferem } \\
\text { probabilidade. }\end{array}$ & pelo Teste de Tukey, a nível de $5 \%$ de
\end{tabular}

TABELA 03. Médias de comprimento $(\mathrm{cm})$ de mesocótilo e coleóptilo e altura de plântulas de dois cultivares de milho, submetidos a diferentes regimes de temperatura.

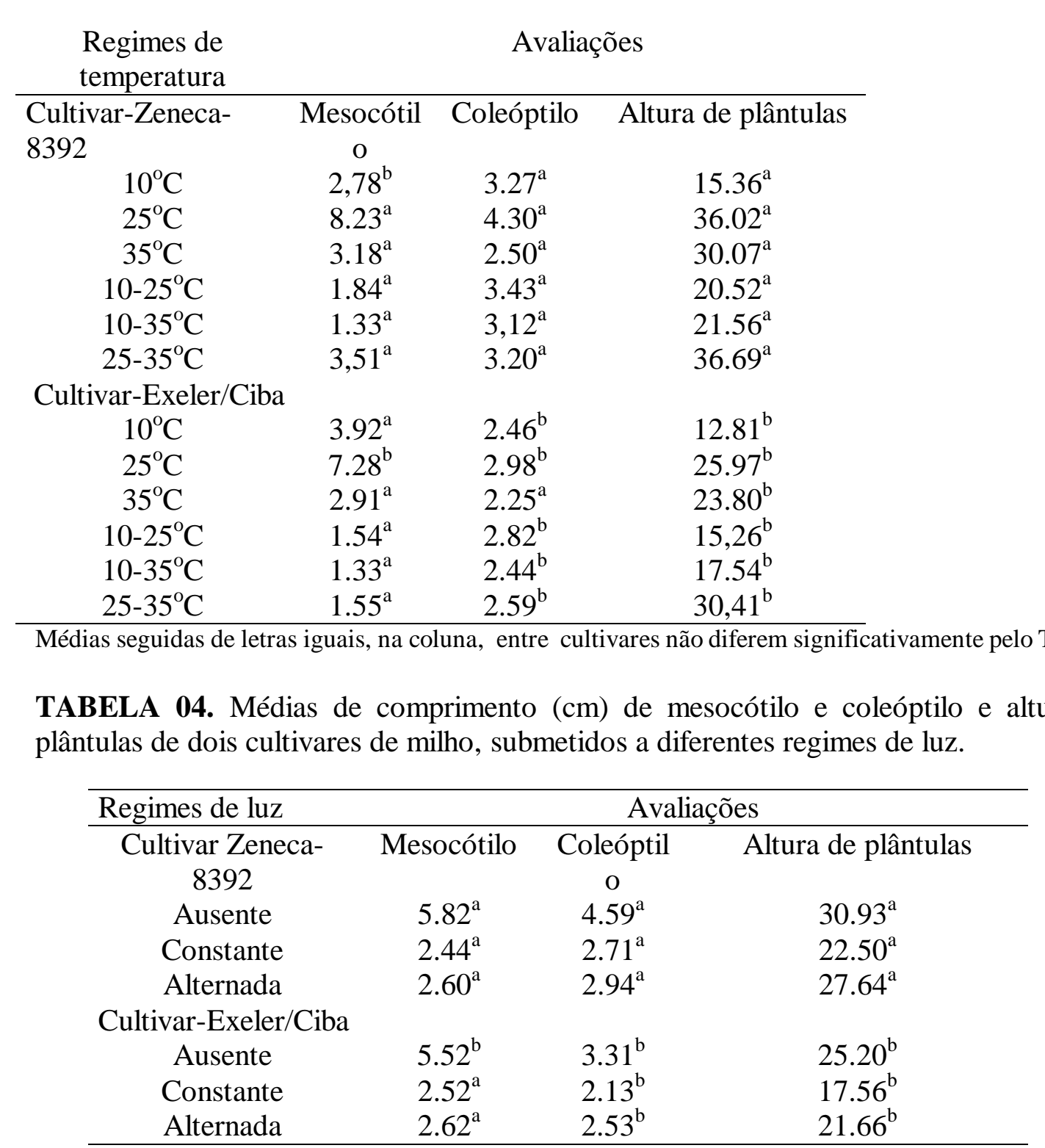

Médias seguidas de letras iguais, na coluna, entre cultivares não diferem significativa mente pelo Teste F. 
TABELA 05. Médias de comprimento $(\mathrm{cm})$ de mesocótilo e coleóptilo e altura de plântulas de dois cultivares de milho, submetidas aos 18 tratamentos. (Continua)

\begin{tabular}{|c|c|c|c|}
\hline Tratamento & Mesocótilo & Coleóptilo & Alt. plântulas \\
\hline \multicolumn{4}{|l|}{ Cultivar-Zeneca-8392 } \\
\hline $10^{\circ} \mathrm{C}$ sem luz & $5.27^{\mathrm{b}}$ & $4.19^{\mathrm{a}}$ & $22.77^{\mathrm{a}}$ \\
\hline $\begin{array}{l}10^{\circ} \mathrm{C} \text { com luz } \\
\text { constante }\end{array}$ & $1.57^{\mathrm{a}}$ & $2.66^{\mathrm{a}}$ & $12.79^{\mathrm{a}}$ \\
\hline $\begin{array}{l}10^{\circ} \mathrm{C} \text { com luz } \\
\text { alternada }\end{array}$ & $1.40^{\mathrm{a}}$ & $2.75^{\mathrm{a}}$ & $7.28^{\mathrm{a}}$ \\
\hline $25^{\circ} \mathrm{C}$ sem luz & $16.28^{\mathrm{a}}$ & $7.42^{\mathrm{a}}$ & $49.27^{\mathrm{a}}$ \\
\hline $\begin{array}{l}25^{\circ} \mathrm{C} \text { com luz } \\
\text { constante }\end{array}$ & $3.91^{\mathrm{a}}$ & $2.59^{\mathrm{a}}$ & $25.38^{\mathrm{a}}$ \\
\hline $\begin{array}{l}25^{\circ} \mathrm{C} \text { com luz } \\
\text { alternada }\end{array}$ & $4.49^{\mathrm{a}}$ & $2.88^{\mathrm{a}}$ & $33.41^{\mathrm{a}}$ \\
\hline $35^{\circ} \mathrm{C}$ sem luz & $3.37^{\mathrm{a}}$ & $3.36^{\mathrm{a}}$ & $14.34^{\mathrm{a}}$ \\
\hline $\begin{array}{l}35^{\circ} \mathrm{C} \text { com luz } \\
\text { constante }\end{array}$ & $3.09^{\mathrm{a}}$ & $2.37^{\mathrm{a}}$ & $23.05^{\mathrm{a}}$ \\
\hline $\begin{array}{l}35^{\circ} \mathrm{C} \text { com luz } \\
\text { alternada }\end{array}$ & $3.26^{\mathrm{a}}$ & $2.63^{\mathrm{a}}$ & $37.09^{\mathrm{a}}$ \\
\hline $10-25^{\circ} \mathrm{C}$ sem luz & $1.61^{\mathrm{a}}$ & $3.41^{\mathrm{a}}$ & $23.93^{\mathrm{a}}$ \\
\hline $\begin{array}{l}10-25^{\circ} \mathrm{C} \text { com luz } \\
\text { constante }\end{array}$ & $1.77^{\mathrm{a}}$ & $3.12^{\mathrm{a}}$ & $16.69^{\mathrm{a}}$ \\
\hline $\begin{array}{c}10-25^{\circ} \mathrm{C} \text { com luz } \\
\text { alternada }\end{array}$ & $2.15^{\mathrm{a}}$ & $3.75^{\mathrm{a}}$ & $20.95^{\mathrm{a}}$ \\
\hline $10-35^{\circ} \mathrm{C}$ sem luz & $1.41^{\mathrm{a}}$ & $3.72^{\mathrm{a}}$ & $22.65^{\mathrm{a}}$ \\
\hline $\begin{array}{c}10-35^{\circ} \mathrm{C} \text { com luz } \\
\text { constante }\end{array}$ & $1.37^{\mathrm{a}}$ & $2.86^{\mathrm{a}}$ & $19.01^{\mathrm{a}}$ \\
\hline $\begin{array}{c}10-35^{\circ} \mathrm{C} \text { com luz } \\
\text { alternada }\end{array}$ & $1.40^{\mathrm{a}}$ & $2.79^{\mathrm{a}}$ & $23.03^{\mathrm{a}}$ \\
\hline $25-35^{\circ} \mathrm{C}$ sem luz & $4.03^{\mathrm{a}}$ & $6.58^{\mathrm{a}}$ & $25.06^{\mathrm{b}}$ \\
\hline $\begin{array}{c}25-35^{\circ} \mathrm{C} \text { com luz } \\
\text { constante }\end{array}$ & $2.95^{\mathrm{a}}$ & $2.64^{\mathrm{a}}$ & $38.08^{\mathrm{a}}$ \\
\hline $\begin{array}{c}25-35^{\circ} \mathrm{C} \text { com luz } \\
\text { alternada }\end{array}$ & $2.86^{\mathrm{a}}$ & $2.77^{\mathrm{a}}$ & $35.96^{\mathrm{a}}$ \\
\hline \multicolumn{4}{|l|}{ Cultivar-Exeler/ciba } \\
\hline $10^{\circ} \mathrm{C}$ sem luz & $6.21^{\mathrm{a}}$ & $3.03^{b}$ & $17.67^{\mathrm{b}}$ \\
\hline $\begin{array}{l}10^{\circ} \mathrm{C} \text { com luz } \\
\text { constante }\end{array}$ & $2.24^{\mathrm{a}}$ & $1.96^{\mathrm{b}}$ & $9.44^{\mathrm{a}}$ \\
\hline $\begin{array}{l}10^{\circ} \mathrm{C} \text { com luz } \\
\text { alternada }\end{array}$ & $1.55^{\mathrm{a}}$ & $2.05^{\mathrm{a}}$ & $7.40^{\mathrm{a}}$ \\
\hline $25^{\circ} \mathrm{C}$ sem luz & $13.13^{\mathrm{b}}$ & $4.33^{b}$ & $35.74^{\mathrm{b}}$ \\
\hline $\begin{array}{l}25^{\circ} \mathrm{C} \text { com luz } \\
\text { constante }\end{array}$ & $4.75^{\mathrm{a}}$ & $2.25^{\mathrm{a}}$ & $18.67^{\mathrm{b}}$ \\
\hline $\begin{array}{l}25^{\circ} \mathrm{C} \text { com luz } \\
\text { alternada }\end{array}$ & $3.97^{\mathrm{a}}$ & $2.36^{\mathrm{a}}$ & $23.51^{\mathrm{b}}$ \\
\hline $35^{\circ} \mathrm{C}$ sem luz & $5.81^{\mathrm{a}}$ & $3.04^{\mathrm{a}}$ & $16.21^{\mathrm{a}}$ \\
\hline $\begin{array}{l}35^{\circ} \mathrm{C} \text { com luz } \\
\text { constante }\end{array}$ & $2.62^{\mathrm{a}}$ & $1.80^{\mathrm{b}}$ & $15.67^{\mathrm{b}}$ \\
\hline $\begin{array}{l}35^{\circ} \mathrm{C} \text { com luz } \\
\text { alternada }\end{array}$ & $3.20^{\mathrm{a}}$ & $2.69^{\mathrm{a}}$ & $31.93^{\mathrm{b}}$ \\
\hline
\end{tabular}


TABELA 05. Médias de comprimento $(\mathrm{cm})$ de mesocótilo e coleóptilo e altura de plântulas de dois cultivares de milho, submetidas aos 18 tratamentos. (Conclusão)

\begin{tabular}{|c|c|c|c|}
\hline $10-25^{\circ} \mathrm{C}$ sem luz & $1.48^{\mathrm{a}}$ & $3.12^{\mathrm{a}}$ & $18.16^{\mathrm{b}}$ \\
\hline $\begin{array}{l}10-25^{\circ} \mathrm{C} \text { com luz } \\
\text { constante }\end{array}$ & $1.56^{\mathrm{a}}$ & $2.56^{\mathrm{b}}$ & $12.61^{b}$ \\
\hline $\begin{array}{c}10-25^{\circ} \mathrm{C} \text { com luz } \\
\text { alternada }\end{array}$ & $1.58^{\mathrm{a}}$ & $2.79^{\mathrm{b}}$ & $15.00^{\mathrm{b}}$ \\
\hline $10-35^{\circ} \mathrm{C}$ sem luz & $1.45^{\mathrm{a}}$ & $2.40^{\mathrm{b}}$ & $21.31^{\mathrm{a}}$ \\
\hline $\begin{array}{c}10-35^{\circ} \mathrm{C} \text { com luz } \\
\text { constante }\end{array}$ & $1.16^{\mathrm{a}}$ & $2.24^{\mathrm{b}}$ & $15.83^{\mathrm{a}}$ \\
\hline $\begin{array}{c}10-35^{\circ} \mathrm{C} \text { com luz } \\
\text { alternada }\end{array}$ & $1.41^{\mathrm{a}}$ & $2.67^{\mathrm{a}}$ & $16.22^{b}$ \\
\hline $25-35^{\circ} \mathrm{C}$ sem luz & $4.53^{\mathrm{a}}$ & $3.48^{\mathrm{b}}$ & $33.35^{\mathrm{a}}$ \\
\hline $\begin{array}{l}25-35^{\circ} \mathrm{C} \text { com luz } \\
\text { constante }\end{array}$ & $2.74^{\mathrm{a}}$ & $1.94^{\mathrm{b}}$ & $31.51^{\mathrm{b}}$ \\
\hline $\begin{array}{c}25-35^{\circ} \mathrm{C} \text { com luz } \\
\text { alternada }\end{array}$ & $3.37^{\mathrm{a}}$ & $2.35^{\mathrm{a}}$ & $27.36^{\mathrm{b}}$ \\
\hline
\end{tabular}

